\title{
PERANCANGAN SISTEM INFORMASI AKADEMIK MENGGUNAKAN METODE PIECES PADA MTS DARUSSA'ADAH JAKARTA
}

\author{
Rusma Insan Nurachim \\ Sistem Informasi Akuntansi, AMIK BSI Tangerang \\ BSD Sektor XIV Blok C1/1, Jl. Letnan Sutopo BSD Serpong \\ rusma.rsc@bsi.ac.id
}

\begin{abstract}
The development of education in Indonesia, experienced a lot of increase. One of them is the use of computers and internet as a means of supporting teaching and learning activities. Some schools have used internet facilities to access course materials, grades and other academic data. As a support for making an application, it needs an integrated system in it. System is a network of procedures in the form of a sequence of activities that are interconnected, gathered together to achieve certain goals. In evaluating the existing system used PIECES method (Performance, Information, Economics, Control, Efficiency and Service) .MTS Darussa'Adah Jakarta is a school that developed since 1990s. The location is quite strategic and qualified teaching staff make MTS Darussa'Adah Jakarta as the choice of some parents for the education of their children. However, the minimal promotional media and data processing is still manual, had caused some obstacles. For that, need to be designed a website that is not only as a medium of advertising, but also as a supporter of academic data processing. The results of this application is displayed data value of students and other data reports.
\end{abstract}

Keywords: Academic Information System, Website, PIECES Method

Intisari - Perkembangan dunia pendidikan di Indonesia, mengalami

\section{Pendahuluan}

\section{A. Latar Belakang}

Sistem informasi akademik bukan hanya situs web yang menyajikan informasi tentang institusi atau sekolah yang bersangkutan. Tapi juga merupakan paket program pengolahan data secara online. Yang diharapkan lebih memudahkan user dalam hal ini adalah guru dan siswa yang banyak kenaikan. Salah satunya adalah pemanfaatan komputer dan internet sebagai sarana penunjang kegiatan belajar mengajar. Beberapa sekolah telah menggunakan fasilitas internet untuk mengakses materi pelajaran, nilai dan data akademik lainnya. Sebagai penunjang pembuatan sebuah aplikasi, dibutuhkan sebuah sistem terpadu di dalamnya. Sistem adalah jaringan kerja dari prosedur-prosedur yang berupa urutan kegiatan yang saling berhubungan, berkumpul bersama-sama untuk mencapai tujuan tertentu. Dalam menevaluasi sistem yang ada digunakan metode PIECES (Performance, Information, Economics, Control, Efficiency and Service).MTS Darussa'Adah Jakarta merupakan sekolah yang berkembang sejak 1990-an. Letaknya yang cukup strategis dan staf pengajar yang mumpuni menjadikan MTS Darussa'Adah Jakarta sebagai pilihan sebagian orang tua untuk pendidikan anak-anaknya. Namun, media promosi yang minim dan pengolahan data yang masih manual, sempat menimbulkan beberapa kendala. Untuk itu, perlu dirancang sebuah situs web yang bukan hanya sebagai media iklan, tapi juga sebagai penunjang proses pengolahan data akademik. Hasil dari aplikasi ini adalah tampil data nilai siswa dan laporan data lainnya.

Kata Kunci: Sistem Informasi Akademik, Website, Metode PIECES

ingin mengetahui informasi akademik terkini. Seperti nilai absen, nilai ujian, nilai tugas bahkan nilai rapor (Kartu Hasil Studi).

Untuk sekolah yang dikelola oleh pihak swasta, belum banyak yang melibatkan prosedur sistem informasi akademik. Dikarenakan sekolah swasta menjadi pilihan beberapa kalangan saja. Kapasitas siswa yang disediakan pun tidak 
sebanyak kapasitas siswa untuk sekolah negeri. Namun ada beberapa sekolah yang mencoba menggunakan situs web sebagai media iklan yang efektif.

MTS Darussa'Adah Jakarta merupakan sekolah yang berkembang sejak 1990-an. Letaknya yang cukup strategis dan staf pengajar yang mumpuni menjadikan MTS Darussa'Adah Jakarta sebagai pilihan sebagian orang tua untuk pendidikan anakanaknya. Namun, dalam prosedur pengolahan data dan media promosi masih ada beberapa kendala yang perlu diatasi. Atas dasar itulah, perlu dirancang sebuah situs web yang bukan hanya sebagai media iklan, tapi juga sebagai penunjang proses pengolahan data akademik.

\section{B. Tujuan dan Kegunaan Hasil Penelitian} adalah:

Adapun tujuan penelitian ini dibuat

1. Merancang aplikasi situs web dinamis guna mempermudah pengaksesan data dan informasi pada MTS Darussa'Adah Jakarta.

2. Untuk mempermudah pengolahan data akademik bagi para siswa dan guru.

3. Sedangkan kegunaan hasil penelitian ini adalah diharapkan situs web yang dirancang bisa lebih efektif dan efisien dalam mengolah data dan menjadi media pendukung perkembangan MTS Darussa'Adah Jakarta.

\section{Pembahasan}

\section{A. Metode}

Melihat sistem prosedur pengolahan data akademik yang berjalan, perlu diadakan beberapa pembaruan yang diharapkan dapat menyempurnakan sistem sebelumnya. Diantaranya adalah membangun sebuah situs web yang berisi semua informasi tentang sekolah tersebut. Agar mempermudah pengolahan data dan membatasi lingkup permasalahan, dalam skripsi ini yang akan dibahas adalah tentang prosedur pengolahan data siswa, pengolahan data guru, prosedur pengolahan data absensi dan pengolahan nilai siswa.

Setelah melihat dan mempelajari sistem berjalan mengenai pengolahan data akademik pada MTS Darussa'Adah Jakarta, berikut analisis permasalahan yang diuraikan menggunakan metode PIECES :

\section{Performance (kinerja)}

Sangat berkaitan dengan produktifitas dari hasil kerja yang dilakukan. Salah satu cara untuk mengukurnya dengan menggunakan troughtput yaitu banyaknya pekerjaan yang dihasilkan dalam satu waktu yang ditetapkan. Troughtput yang dihasilkan oleh sistem berjalan dalam pencarian data dan penyajian laporan membutuhkan waktu \pm 2 hari. Sehingga apabila dibutuhkan laporan cepat saji, tentunya kurang terlaksana dengan baik. Dengan menggunakan sistem informasi akademik berbasis web ini, maka laporan dapat langsung di akses oleh pihak yang membutuhkan.

\section{Information (informasi)}

Informasi yang disajikan harus berkualitas, dimana informasi harus akurat, relevan dan tepat waktu. Pada sistem berjalan bentuk informasi dalam hal ini adalah laporan sudah cukup akurat dan relevan. Hanya saja kurang tepat waktu dalam penyelesaiannya dikarenakan berbagai kendala. Aplikasi ini membantu memudahkan dalam memperbarui informasi karena dapat diakses dan diperbarui secara langsung.

\section{Economy (ekonomi)}

Meskipun dalam bidang pendidikan, keuntungan perlu ditingkatkan. Hal ini bertujuan agar kinerja tidak terhambat karena kesulitan ekonomi. Dalam pembuatan laporan pada sistem berjalan masih ditemukan beberapa kesalahan. Sehingga jika itu terjadi, maka akan terjadi pemborosan untuk membuat laporan yang baru. Berkat adanya sistem informasi akademik berbasis web ini, kesalahan dapat diminimalisir dan lebih cepat dalam menyajikan laporan yang dibutuhkan.

\section{Control (kendali)}

Control digunakan untuk meningkatkan dan menambah aliran informasi dan kinerja sistem, mencegah atau mendeteksi penyalahgunaan atau kesalahan sistem dan menjamin keamanan data. Pada sistem berjalan kendali dipegang penuh oleh staff tata usaha. Pada sistem yang berbasis web ini kendali dapat dilakukan dari jarak jauh, sehingga staff tata usaha dapat mengoptimalkan kinerjanya.

\section{Efficiency}

Efisiensi berbeda dengan ekonomis. Bila ekonomis berhubungan dengan menguntungkan atau tidak suatu sistem, 
efisiensi berhubungan dengan bagaimana sumber daya tersebut digunakan seminimal mungkin. Pada sistem berjalan pendayagunaan waktu masih kurang efisien, yaitu lamanya waktu yang diperlukan untuk mencari data, sehingga menghambat kegiatan lain yang berhubungan. Sedangkan dengan menggunakan sistem berbasis web ini efisiensi dapat ditingkatkan karena tidak memerlukan waktu yang lama melakukan pencarian data.

\section{Service (pelayanan)}

Pemberian pelayanan yang ada dinilai masih kurang memuaskan karena sering lambatnya dalam menangangi kebutuhan akademik para siswa. Sistem informasi akademik berbasis web ini dapat meningkatkan pelayanan terhadap siswa karena informasi dapat diperbarui dan diakses secara realtime.

\section{B. Permasalahan}

Berikut diuraikan mengenai berbagai permasalahan yang ada di lapangan:

1. Bagaimanakah proses pengolahan data akademik yang ada pada sistem berjalan?

2. Bagaimanakah prosedur pendaftaran siswa baru?

3. Media apakah yang digunakan dalam proses penyampaian informasi dari sekolah kepada staf pengajar dan para siswa?

4. Apakah media iklan yang digunakan untuk mempromosikan sekolah?

5. Bagaimanakah proses pengolahan data nilai siswa?

6. Bagaimanakah pengelolaan data administrasi bagi setiap siswa?

7. Seberapa mudah siswa dapat mengakses informasi tentang data akademik untuk siswa yang bersangkutan?

8. Apakah guru dapat dengan mudah untuk mengolah nilai siswa?

\section{Deskripsi Sistem Usulan}

Adapun rancangan sistem usulan yang akan diberikan, dapat digambarkan dalam dekomposisi sebagai berikut:

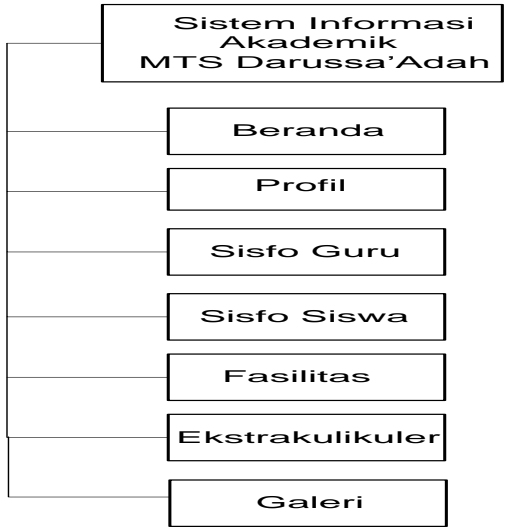

Sumber: Rusma(2018)

\section{Gambar 1 Dekomposisi Sistem Usulan}

\section{Use case diagram}

Use case diagram merupakan pemodelan untuk kelakuan (behavior) sistem informasi yang akan dibuat. Use case diagram menggambarkan sebuah interaksi antara satu atau lebih aktor dengan sistem informasi yang akan dibuat. Dengan kata lain, use case digunakan untuk mengetahui fungsi apa saja dan siapa saja yang ada dan berhak menggunakan fungsi-fungsi di dalamnya.

\section{a. Use Case Diagram Akademik}

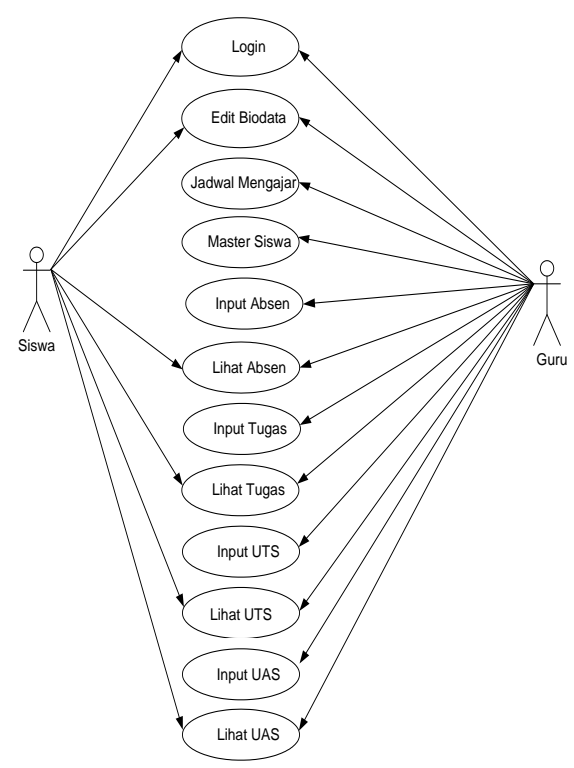

Sumber: Rusma(2018)

Gambar 2. Use Case Diagram Akademik 
D. Activity Diagram

1. Activity Diagram Input Data Siswa

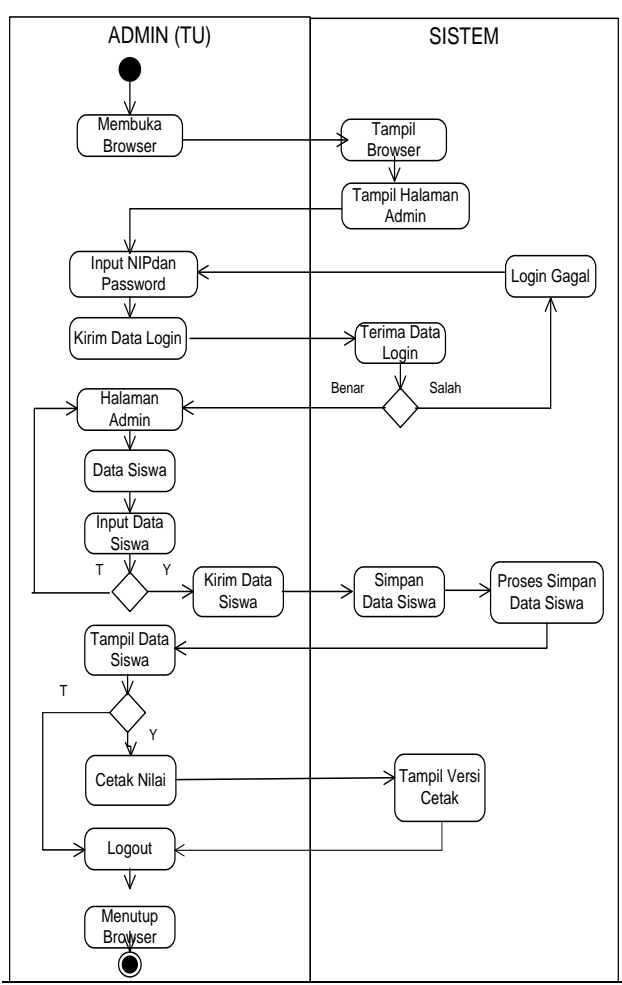

Sumber: Rusma(2018)

Gambar 3 Activity Diagram Input Data Siswa

\section{Activity Diagram Input Data Guru}

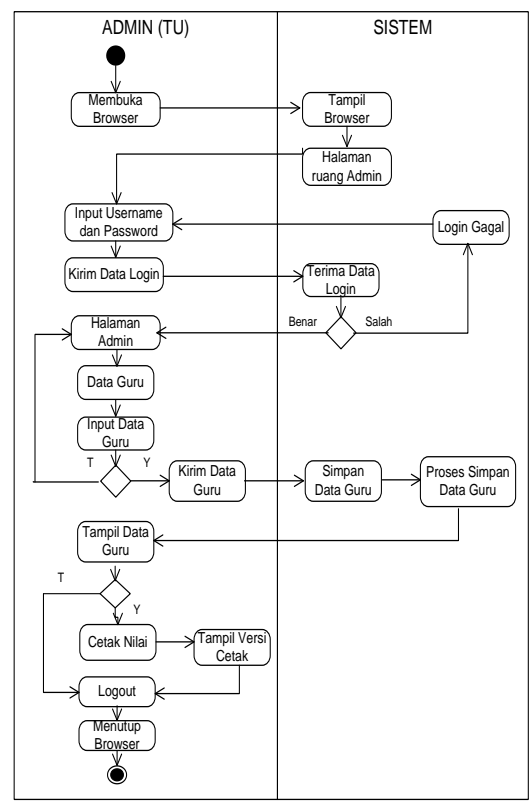

Sumber: Rusma(2018)
Gambar 4 Activity Diagram Input Data Guru

\section{E. Spesifikasi Modul \\ 1. Class Diagram}

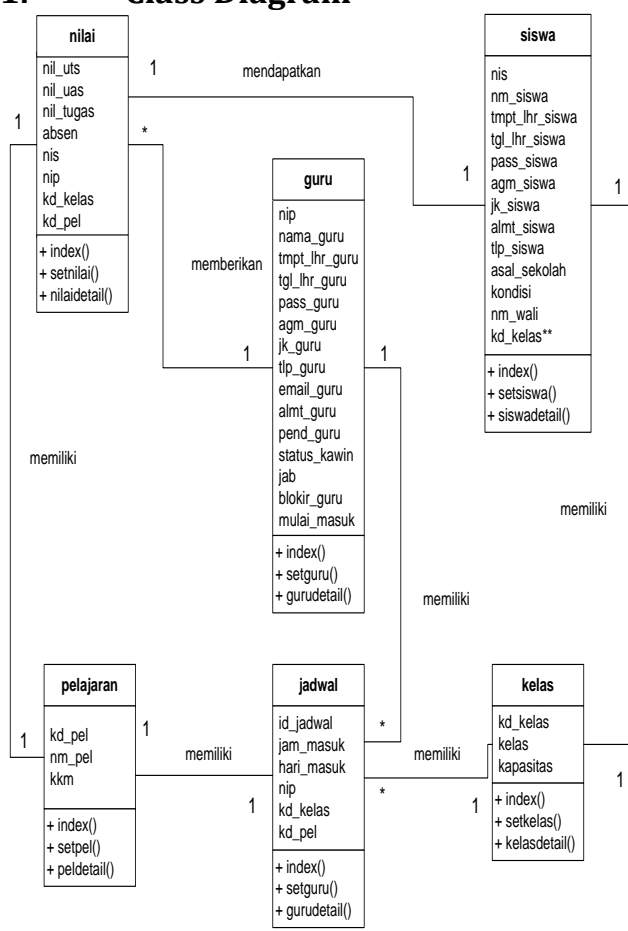

Sumber: Rusma(2018)

Gambar 5 Class Diagram

\section{Entity Relationship Diagram}

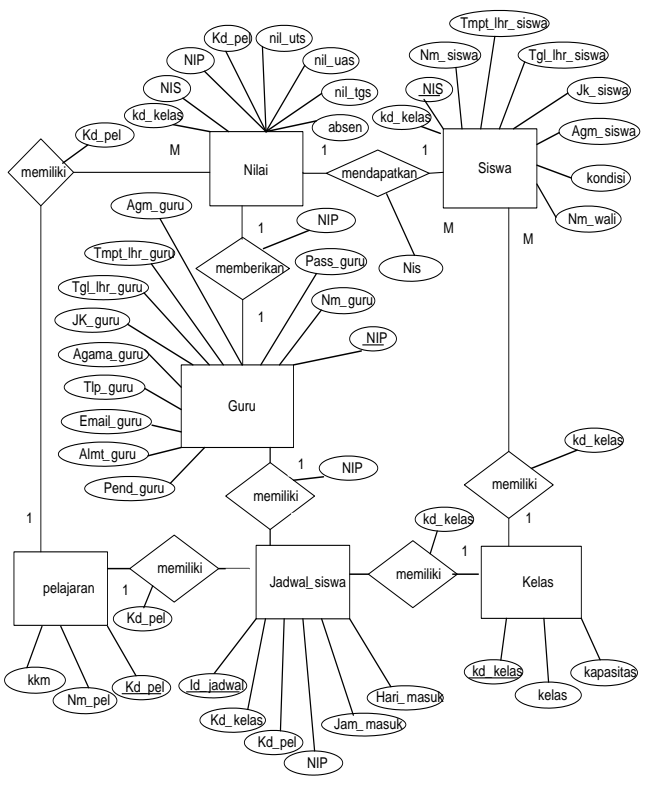

Sumber: Rusma(2018) 


\section{Gambar 6 Entity Relationship Diagram} (ERD)

F. Rancangan Tampilan

1. Halaman Index

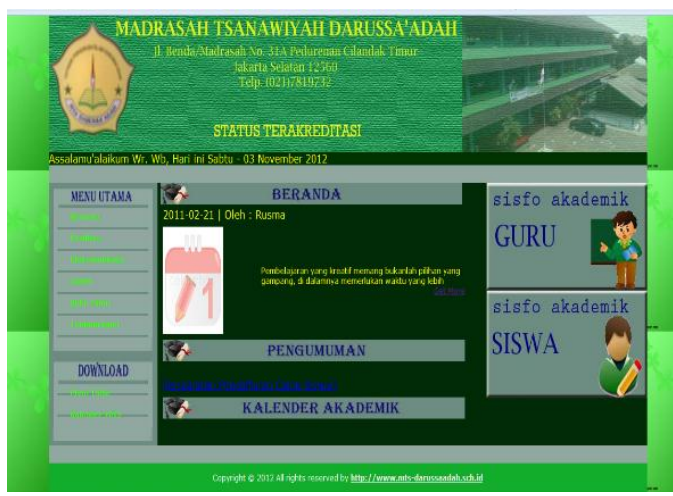

Sumber: Rusma(2018)

Gambar 7 Halaman Index/Beranda

2. Halaman Login Guru

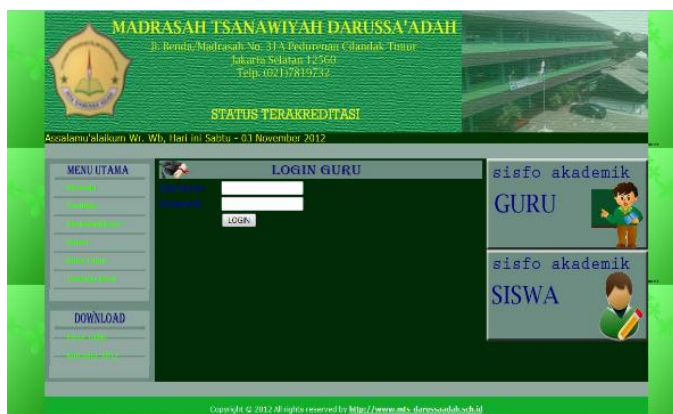

Sumber: Rusma(2018)

Gambar 8 Halaman Login Guru

3. Halaman Index Guru

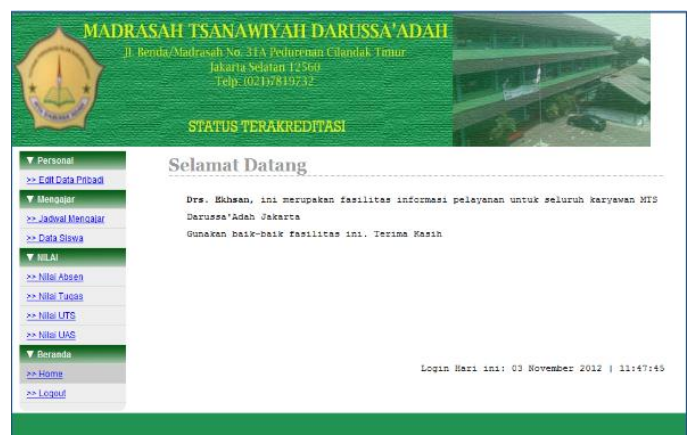

Sumber: Rusma(2018)

Gambar 9 Halaman Index Guru
4. Halaman Login Admin

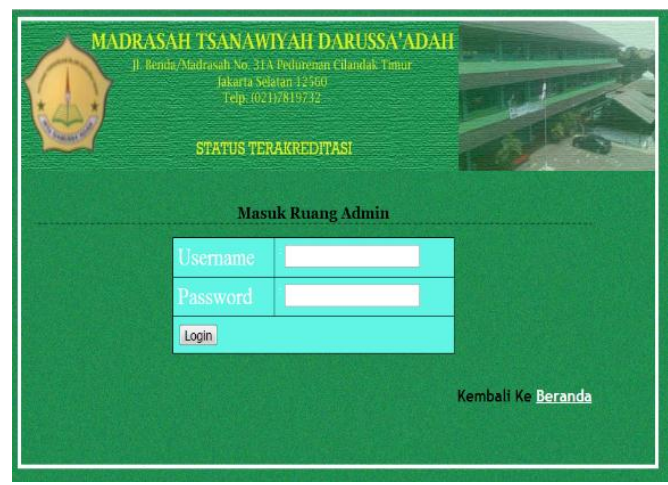

Sumber: Rusma(2018)

Gambar 10 Halaman Login Admin

5. Halaman Index Admin

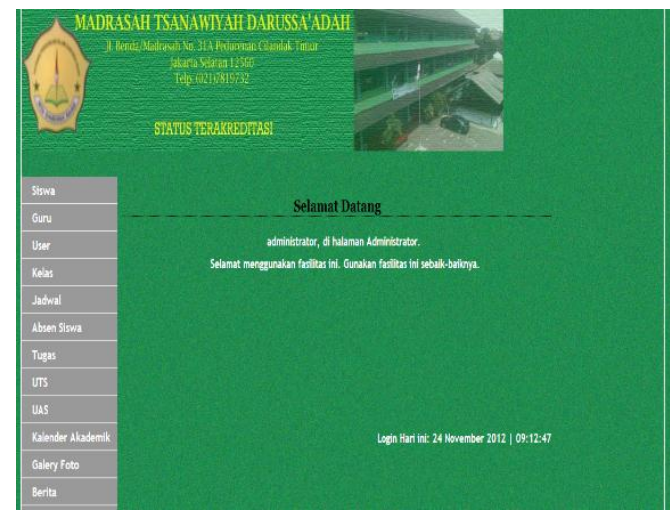

Sumber: Rusma(2018)

Gambar 11 Halaman Index Admin

6. Halaman Laporan Data Guru

MADRASAH TSANAWIYAH DARUSSA'ADAH

Jl. Benda/Madrasah No. 31A Pedurenan Cilandak Timur Jakarta Selatan 12560
Telp. $(0217889732$

DATA GIRU

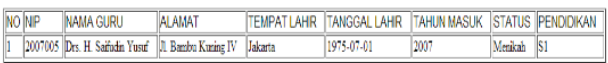


Sumber: Rusma(2018)

Gambar 12 Laporan Data Guru

\section{Kesimpulan}

Dari beberapa hal yang telah dibahas pada sebelumnya, maka dapat ditarik kesimpulan sebagai berikut:

1. Dengan adanya sistem informasi akademik berbasis web ini siswa bisa mengetahui informasi seputar kegiatan belajar mengajar di sekolah seperti jadwal pelajaran, nilai-nilai akademik yang didapat di sekolah dan informasi lainnya tentang akademik sekolah.

2. Pihak sekolah terutama guru-guru bisa melakukan penilaian akademik siswa di website ini.

3. Administrator dalam hal ini TU bertugas untuk manajemen website informasi akademik sekolah seperti membuat, menjaga dan mengupdate website, bekerja sama dan mensupport anggota lain dalam maintaining website, membuat website lebih ramah dan mudah (users friendly), memastikan server website tetap hidup, kualitas dan style website dalam sistem.

4. MySQL sebagai server database untuk aplikasi PHP. Kemudahannya dalam integrasi ke berbagai aplikasi web (terutama $P H P$ ) cukup membantu dalam pengembangan sistem Informasi akademik sekolah secara online.

Dalam teknologi pemrograman aplikasi berbasis web yang telah dikembangkan, $P H P$ dapat dijadikan sebagai salah satu pilihan utama dalam pembuatan aplikasi berbasis web karena keunggulannya dan kemudahan dalam pemakaian.

Adapun saran-saran yang dapat disampaikan adalah sebagai berikut :

1. Aplikasi web yang telah dibuat hendaknya dioperasikan secara baik dan benar untuk mencapai tujuan yang diharapkan.

2. Pemakai komputer (user) lebih mengutamakan pengetahuan tentang hardware dan software secara seimbang. Dalam membantu kelancaran penerapan teknologi komputer serta paham tentang teknologi berbasis internet serta teknologi client server. Untuk itu perlu diadakan pelatihan / training kepada user, agar dapat mengurangi kendala dalam pengoperasian website.

3. Untuk meningkatkan kinerja serta untuk mengembangkan aplikasi ini maka sebaiknya diadakan pengembangan aplikasi mulai dari tampilan halaman web sampai dengan maintenance-nya.

4. Pada periode tertentu perlu adanya pengecekan data kembali untuk menjaga segala kemungkinan timbulnya kelemahan.

\section{Daftar Pustaka}

A.S, Rosa, M. Shalahuddin. (2011). Rekayasa Perangkat Lunak. Bandung: Modula.

Dayana, Siska. (2011). Perancangan Sistem Informasi Akademik Berbasis Web Pada SMA Bina Putra Bangsa Depok. Jakarta.

Nugroho, Bunafit. (2008). Membuat Aplikasi Sistem Pakar dengan PHP dan Editor Dreamweaver. Yogyakarta: Gava Media.

Widodo. (2010). Sistem Informasi Akademik Penilaian Siswa Pada Madrasah Aliyah Al Falah Jakarta Timur. Jakarta.

Susanti, M. (2016). Perancangan Sistem Informasi Akademik Berbasis Web Pada Smk Pasar Minggu Jakarta. Informatika, 3(1), 91-99.

Ridho, S. (2012). Rancang Bangun Sistem Informasi Akademik SMK Triatma Jaya Semarang. Jurnal Dinamika Informatika, 4(1), 41-50. Retrieved from

http://www.unisbank.ac.id/ojs/index .php/fti2/article/view/3762 